\title{
Nature versus Nurture in Bilinguals' Language Acquisition
}

\author{
Lin $\mathrm{Gao}^{1, *}$ \\ ${ }^{1}$ Department of psychology, The University of Maryland, College Park, Maryland, United States, 20740 \\ *Corresponding author. Email:lgao123@terpmail.umd.edu
}

\begin{abstract}
Nature versus nurture is a controversial question in psychology. Many psychologists are debating whether genes or experience play a more important role in human development. Some researchers emphasize the influence of learning on language acquisition, while others emphasize biological influences. Language is the way that humans could use to convey their thoughts and communicate with each other. But the question is that is language innate or learned? This paper does not pay much attention to the role of genes and experience in the overall development of human beings, but this study aims to explore what role they play in the development of language. The researcher would explore this question based on the bilingual's language development. That is because bilingual speakers can be proficient in both languages, which allows us to examine the influence of their innate and acquired environment on their language development. The researcher has studied and analyzed the previous academic papers and examples about the nature versus nurture of language and summarized them to draw the conclusion of this paper. It can be concluded that both nature and nurture play an important role in the development of language acquisition. This is because we need our genes and brain to build a language acquisition device (LAD), and then, after we have the ability to learn a language, our acquired environment acts on our language system. As we interact with people around us later in life, we gradually acquire words and grammar, and our language system is then complete.
\end{abstract}

Keywords: Nature vs. Nurture, Language acquisition, behaviorism, nativism, Bilingual

\section{INTRODUCTION}

It has long been debated which role is more important throughout human development, nature or nurture [1]. Nature refers to all the genetic factors that influence us, from our appearance to our personality traits. Whereas nurture refers to all the environmental variables that influence us, including our childhood experiences, the way we were raised, our social relationships, and the culture around us [2]. Although most researchers acknowledge that both nature and nurture play an important role in language acquisition, however, some researchers emphasize the influence of learning on language acquisition, while others emphasize the influence of biology. This paper would collect viewpoints from different researchers and analysis each of them, and then, the researcher would conclude all their perspectives and get the final point of view.

This is an interesting question because, in the future, it could help parents who want their child to be a bilingual speaker to design better parenting for their child. This could help their children become bilingual more quickly and easily.

\section{ANALYSIS}

Nature versus nurture which plays a more important role in language acquisition has been debated for centuries. Some theorists believe that language skills are built directly into our brains, just like our fingers and arms, and that we are born with the ability to use them skillfully. However, other theorists believe that because we have a well-developed and mature brain, we can learn languages later in life.

\subsection{Nurture}

Skinner [3] provided one of the earliest scientific explanations of language acquisition. As one of the pioneers of behaviorism, he explained language development through environmental influences, which means that he thinks nurture plays a more important 
role in language development. Skinner believed that children learn language based on the behaviorist principle of reinforcement through the association of words and meanings. When children become aware of the communicative value of words and phrases, correct discourse is positively reinforced. Skinner believed that humans have the ability to speak because we have the time, opportunity, and (perhaps) computational ability to learn a very large number of words and the associations that tie those words together.

A documentary directed by Tim Wardle is called "Three Identical Strangers," told a story about an accidental reunion of three identical triplets at the age of 19. The triplets were adopted by three different families when they were six months old. During the adoption process, none of the families were told that the children they were about to adopt were the triplets of the other two living children. Their reunion caused a sensation in the early 1980s, with the three young people making the front pages of newspapers and magazines and being invited to several talk shows. Everyone, including the triplets, was shocked at how many traits and interests they had in common. The first part of the documentary presents the influence of genetics on the development of behavioral traits and interests.

Beyond some superficial similarities, such as favorite sports and food tastes, all three boys grew up to be different people in terms of social skills, work ethic, and coping styles. All of this is acquired through verbal interaction with others. Thus, the three identical twins developed so differently because of the environment in which they were raised later in life. It looks that it supports Skinner's view.

There is a kind of bilingual parents who brought their children to another country whose language is different from the country they moved out of. This means that they were born without different language mechanisms in their language acquisition device (LAD). But as the children spend more time in the country, they immigrated to, and the children gradually begin to acquire the other language. For example, a child moves from China to the United States.

It is important to understand that Chinese and English are two completely different languages. Children who speak Chinese become proficient in English because they have been in an English-speaking environment long enough and have teachers who help them learn English words and grammar. This means that they also become bilingual. This example again supports Skinner's point.

\subsection{Nature}

However, nativist theorists argue that human abilities and developmental processes are innate and hardwired at birth. These theories provide beliefs about the developmental processes most closely associated with initial language acquisition [4]. After Skinner's views were published, he was soon severely criticized by Noam Chomsky, by far the world's most famous linguist. According to Chomsky, children are born with a language acquisition device (LAD), a specialized, purposeful, language-only evolutionary learning device that is hardwired in children's brains, enabling them to acquire language and use grammar [5]. Besides that, "Native theories support this concept and argue that if the native language is not learned before this age, it cannot be learned in a normal, natural way and cannot reach a fully functional state [4]."

Some bilinguals have parents from different countries, meaning that each parent speaks a different language. According to Chomsky's theory, these children are born with genes inherited from their mothers and fathers, which means that they are born with two different language mechanisms in their language acquisition device (LAD). Therefore, these children have an advantage over the average child in the language learning process.

\subsection{Summary}

From this, this research concluded that both nature and nurture are important in the development of language. This is because people first have to have the ability to learn languages (nature), and then, when they are able and in a language environment (nurture), they can begin to speak it after a long period of listening and speaking training. Just like Chomsky said, children are born with a language acquisition device (LAD) which allows them to have the ability to acquire language and use grammar.

This is a prerequisite for children to develop language skills. Then, as Skinner said, children need to be immersed in a language environment, which means that their parents need to speak and interact with them. This is how the children's language acquisition device (LAD) can begin to come in handy. Bilinguals speakers whose parents each speak a different language will begin to imitate two different languages in their innate environment. From there, they continue to work on their ability to speak both languages as they grow up. Then they will gradually begin to become proficient in both languages as they grow up. Even deaf children have the ability to create their own language so that they can communicate with others [6].

\section{FUTURE WORKS}

Finding a reliable answer to the question of language acquisition is far from over. Our current understanding of the developmental process is still immature. The process by which children learn a language and translate it into a grammatically correct 
adult language is not fully understood. Nor does it lead to a completely correct and reasonable explanation of whether bilingual speakers learn a second language in exactly the same way as they learn their first language. Although the present paper has produced a relatively acceptable discussion of nature and nurture questions, it has not been possible to reach a fully valid and reasonable explanation.

However, this does not mean that future researchers will not break new ground in this area. In the future, researchers can focus more on the linguistic implications of innate and acquired research.

Because language is a form of communication unique to humans as higher animals, it can even be called the greatest treasure of mankind. Although people are not born as great literary figures as Shakespeare, we can speak and communicate, something that all people can do.

Although much research has been done to show that the language center of the brain is composed of Broca's area, Supramarginal gyrus, Wernicke's area, Primary auditory cortex, and Angular gyrus, researchers can go further to investigate the specific mechanisms of the language acquisition device (LAD) as described by Chomsky. This would provide a more concrete theoretical basis for the nature versus nurture discussion.

\section{CONCLUSION}

This paper examines whether nature or nurture plays a greater role in the development of a child's language acquisition. The conclusion based on the ideas and perspectives mentioned in the previous paper is that both innate and acquired play an important role in language development. Parents and the people around the child interact with the child linguistically during early development. Language functions are gradually established during these interactions, and their ability to acquire language is continuously developed over time. Eventually, they become proficient in one or more languages.

As children grow, their language skills are gradually influenced by those around them, such as their parents, grandparents, friends, and teachers. For example, both the United States and the United Kingdom speak English, but children have different accents and linguistic preferences because of their environments and genetics. American children prefer to call the houses that students rent temporarily "apartments," while British children prefer to call them "flats." This is an effect of their environment. But that doesn't mean that genes don't have an effect on language development.

We still need a language acquisition device (LAD) to help us acquire the ability to learn languages. Without this "device," we would lose the ability to acquire language. It's like asking whether baseball or the bat is more important in baseball.

Therefore, both nature and nurture play a major role in our language system, which means that both innate genes and acquired environment and experience are necessary for the formation of language. Without either of them, we have no way to form a sound language system. Both of them are really important, and one cannot be missing, and they are balancing each other. This is how we can master and apply language proficiently.

\section{AUTHORS' CONTRIBUTIONS}

This paper is independently accomplished by the author.

\section{ACKNOWLEDGMENTS}

In successfully completing this project, many people have helped me. I would like to thank all those who are related to this study.

I would especially like to thank my university: the University of Maryland, College Park. I learned a lot from the university and without my studies at UMD, it would have been difficult for me to complete this research on my own.

I must also thank my parents and friends for their tremendous support and help during this project. Without their help, completing this project would have been very difficult.

\section{REFERENCES}

[1] Mcleod, Saul. "Nature vs. Nurture in Psychology." Nature Nurture in Psychology,Simply Psychology, 2018 ,

[2] Cherry, Kendra. "What to Know about Nature vs. Nurture." Verywell Mind, June 3, 2020.

[3] Skinner, B. F. Verbal Behavior. The Century Psychology Series. New York: Appleton-Century-Crofts, 1957.

[4] Goldstein, Sam, and Jack A Naglieri. Encyclopedia of Child Behavior and Development. Springer, 2011 .

[5] Chomsky, Noam. Aspects of the Theory of Syntax. M.I.T. Press, 1965.

[6] Emmorey, Karen. Language, Cognition, and the Brain : Insights from Sign Language Research. Lawrence Erlbaum Associates, 2002. 